\title{
Socio-economic Performance of Manufacturing Companies in Urban Ghana
}

\author{
Kwame B. Bour ${ }^{1} \quad$ Henry Kofi Mensah ${ }^{2} \quad$ Akowuah Jones Asafo $^{3} \quad$ Jonathan Mensah Dapaah $^{4}$ \\ 1. [Corresponding Author] Department of Social Sciences, SDA College of Education, Agona Ghana \\ 2. Department of Human Resource and Organisational Development, Kwame Nkrumah University of Science \\ and Technology, Kumasi, Ghana \\ 3. Department of Agricultural Economics, Agribusiness and Extension, Kwame Nkrumah University of Science \\ and Technology, Kumasi, Ghana \\ 4. Department of Sociology and Social Work, Kwame Nkrumah University of Science and Technology, Kumasi, \\ Ghana
}

\begin{abstract}
The integration of sustainable development practices including environmental management accounting, environmental performance assessment, social equity, economic efficiency and corporate social performance into the daily management portfolios of business has acted as the catalyst towards the socio-economic performance of businesses. This paper explored the effects of environmental sustainability practices on socio-economic performance of manufacturing companies in urban Ghana. The study involved six manufacturing companies. Using the cross-sectional design with a two-stage sampling technique, 600 respondents were selected from the 6 companies. The hypothetical model was tested using regression analysis, to verify the hypothetical relationships between variables in the study. A 2-tailed test involving Pearson product-moment correlation coefficient was run to ascertain the relationship between ESPs and economic performance of MCs. The results of the study from the model Summary showed R Square of 0.813 indicating that about $81 \%$ of the socio-economic performance of manufacturing companies is accounted for by environmental sustainability practices (ESPs). There is a significant negative profit margins in the operational activities of companies (-0.550) at 0.01 due to ESPs in the company. It is concluded that environmental sustainability practices relate to socio-economic performance of manufacturing companies.
\end{abstract}

Keywords: Environmental sustainability practices, environmental accountability, corporate sustainability performance, environmental citizenship, environmental injustice, manufacturing companies, Ghana

DOI: $10.7176 / \mathrm{EJBM} / 11-15-09$

Publication date:May $31^{\text {st }} 2019$

\section{Introduction}

The environments of modern manufacturing companies have proved to be less secure with difficult and complex operations (Andrew et al., 2016). As a result, their competitiveness has been enormous in relation to the crosscutting demands consumers expect from them (Paiva et al., 2012). This has caused most companies to focus on flexible strategies on their production processes to be sustainable in operations, while neglecting the sustainability of the environment and ecosystem they operate in. Therefore, the effect of environmental sustainable practices (ESP) on the socio-economic performance of manufacturing companies are of much value towards their continuous survival in the environments they operate (Kouakou, 2013).

There are global calls in most international fora on the need for companies to operate with universal guidelines on the adoption of environmental practices (Sarfo-Mensah and Oduro, 2007; Nawrocka and Parker, 2009; Montobbio et al., 2010). These regulatory principles help to ensure both internal and external sanity in operations and corporate sustainability (Hörisch et al., 2014). Several forces contribute to this interest of environmental compliance by manufacturing companies while ensuring better socio-economic performances. Regulations from the international economic environment dictate that rules governing manufacturing companies are reorganised (Boons, 2013). A number of long-term challenges including scarcity of raw materials, desertification, climate change and pollution (Montalvo et al., 2006) necessitated this arrangement.

Environmental problems is said to be prevalent in manufacturing areas all over the world and that there is a growing concern about the ever-increasing environmental degradation due to industrial activities (Sarkis, 2017; Masrom et al., 2018). Several manufacturing industries discharge organic and inorganic wastes into the environment especially into water bodies. These include acids, highly toxic minerals, such as mercury or arsenic, or toxic organic chemicals. Such environmental injustice can have negative effects such as rendering water unsafe for domestic use and even for irrigation. The pollutants may enter the food chain and cause health complications for humans and animals (Carter, 2001; Songsore, 2004). In Ghana, companies submit their environmental sustainability practices and plans as mandatory requirement for their registration, which is the baseline level of their establishment. Despite Ghana's involvement in major UN ratifications on the environment and its economic activities, most manufacturing companies still lag behind in their socio-economic performance. 
From the foregoing discussions, Ghana has then committed herself to the entire major UN resolutions relating to the environment, including the United Nations Framework Convention on Climate Change (UNFCCC), of which the national government considers important in its development planning. To demonstrate the commitment of the Government of Ghana to environmental protection and sustainability, Act 490 established Environmental Protection Authority (EPA), formerly called Environmental Protection Council, in 1994 to regulate all economic or otherwise activities that affect the environment in anyway in the country. A subsequent law; Environmental Assessment and Regulations (LI.1652) was passed. These legal instruments made it mandatory for companies and enterprises to submit their environmental management plans or intended practices as a requirement for registration. The already existing ones are also expected to conduct annual environmental impact assessment for consideration by the EPA. Nevertheless, these interventions have not yielded any positive result and seemed to have had negative implication for socio-economic performance of MCs.

Poor socio-economic practices of manufacturing companies still prevail among major companies in Africa, despite a comprehensive environmental guidelines outlined by the United Nations Environmental Programme (UNEP) in 2007. This has enormously contributed to a number of sustainability issues including ecology and health in major areas of the sub-region (Songsore, 2004, Sarfo-Mensah and Oduro, 2007; Kouakou, 2007; Mayamurugan, 2016). Hence, there is the need to take pragmatic measure to control and manage wastes from production sites. Even though some studies have been conducted in this area, they have their own gaps for which a comprehensive research ought to be done which would cover broad dimensions of the socio-economic performance of manufacturing companies. The work of Kouakou (2013) considers only how cocoa crops demanded by manufacturing companies are destroying the forest reserves and ecology of Ivory Coast. In their work on the effects of manufacturing industry on the environment, a case of Atonsu-Kaase-Ahinsan in the Ashanti Region of Ghana, Kpelle et al., (2014) focused exclusively on geographical location. Similarly, Mayamurugan in his work on integrated waste management in India broadly reports on the environmental management system in general using the ISO 14001 package.

Actually, environmental degradation and pollution assumed an alarming rate with the advent of industrial revolution. Industrialisation, manufacturing for that matter, was seen as sine qua non for development and for that reason, industrial activities were not based on sustainable development (Akuoko and Bour, 2013). In this respect, manufacturing of goods was seen as a means to development without critically considering the environmental repercussions they pose.

Furthermore, EPA-AKOBEN environmental sustainability practice rating of manufacturing companies in Ghana (2012) revealed that many of the organisations assessed scored very badly on the environmental protection indicators such as hazardous waste management, toxic releases, non-toxic releases, monitoring and reporting environmental best practices, community complaints and corporate social responsibility. In fact, only two companies (Ghana Rubber Estate Ltd and Diamond Cement) in the manufacturing sector were rated very good throughout the country. Moreover, almost all the manufacturing companies in the Ashanti Region were rated red (unsatisfactory).

Environmental hazard emanating from the manufacturing companies in the Ashanti was also observed when chemical spillage from the Abuakwa Formulation Plant in the Atwima District caused health and discomfort to the inhabitants in the catchment areas. Kpelle et al (2014) that companies in the wood processing sector empty their waste into nearby streams also identify it.

Following these ecological experiences are a series of 'why' socio-economic performance of manufacturing companies needs to be examined critically. In the first place, companies submit their plans on environmental sustainability practices or plans as mandatory requirement prior to their registration. Therefore, by this requirement one expects every manufacturing company to be on top of environmental sustainability practices. Notwithstanding, how come that these same companies fail the test on the implementation of the very thing they professed to apply at the workplaces? Is it because, it is a mere requirement to present such documents for incorporation? Why have companies failed the test they have set for themselves? Does that mean that what they present to the EPA is different from what they actually practice? Something is missing, that social fact, that explanation is needed urgently by means of a scientific research. Though many companies have failed to comply by the socio-economic performance guidelines in Ghana, there is very little data available in the study area. Hence, this study is aimed at filling the gaps on 'why' most companies fail to observe environmental regulations in business settings they are located. Yet are able to break even and make profits while their counterparts that strictly adhere to environmental sustainability regulations do not make profits.

\section{Data and Methods \\ Study setting}

Ashanti region, which is the target region of this study, is centrally located in the middle belt of Ghana and lies between longitudes $0.15 \mathrm{~W}$ and $2.25 \mathrm{~W}$, and latitudes $5.50 \mathrm{~N}$ and $7.46 \mathrm{~N}$. It shares boundaries with four of the sixteen political regions including Brong-Ahafo to the north, Eastern region to the east, Central region on the south and 
Western region in the Southwest. The region is said to occupy a total land area of 24,389 square kilometres representing 10.2 per cent of the total land area of Ghana. It is also the most populous region with a population of 4,780,280, representing 19.4 percent of the country's total population (GSS, 2012) and a population density of 148.1 persons per square kilometres. More than half of the region's territory lies within the wet, semi-equatorial forest zone. History has it that the region was carved out of the Asanteman (Ashanti nation) founded during the reign of King Osei Tutu I (1697-1718) with Kumasi as its administrative capital (GSS, 2012). As of 2016, the region had 30 districts including 4 municipalities and Kumasi metropolis with 47 constituencies. The traditional head of the region is the Asantehene but the political head is the Regional Minister.

The target industrial sector of this study was the manufacturing sector in the Ashanti Region of Ghana. Manufacturing companies in the Ashanti region were chosen for this study due to their abysmal performance in environmental sustainability practices assessment according to the EPA (EPA-AKOBEN, 2012). There were other economic sectors in the region whose activities also affected the physical environment badly and needed to have been studied though, the EPA (2012) report indicated that manufacturing organisations in the Region grossly failed to meet environmental sustainability standards. Ironically, these organisations profess to have environmental sustainability practices.

For the purpose of this study, only those companies rated red by the EPA in 2012 were selected except CocaCola Bottling Company, Ghana which was selected even though it was rated satisfactory. It was meant to serve as a control group because it had best practices. Moreover, since these organisations are concentrated in Kumasi, five of them were selected from within Kumasi and one was selected from Juabeng. They were selected based on the major manufacturing industries in the region that they belong to. The organisations were clustered into industries engaging in wood processing, chemical production, agro business, food, oil and drinks processing. The classification was done in accordance with the advice of the public relations officers of EPA in Kumasi. From these Clusters, the study organisations were then selected purposively from a list of 14 organisations listed with EPA-Ghana for environmental assessment in 2012.

Table 1: List of Selected Organisations

\begin{tabular}{|l|l|l|}
\hline Type of Manufacturing org. & Name of the organisation. & Staff strength \\
\hline Wood Processing & Bibiani Logs and Lumber Co. Ltd (BLLC) & 300 \\
\hline Animal Feeds Processing & Agricare Co. Ltd (AC) & 186 \\
\hline Chemical Production & Amponsah Effah Pharmaceuticals Ltd (AEP) & 224 \\
\hline Food Processing & Kumasi Abattoir (KA) & 159 \\
\hline Oil Processing & Juabeng Oil Mills (JOM) & 187 \\
\hline Drinks and Beverages & Coca-Cola Bottling Co. Gh (CBC) & 360 \\
\hline Total & & 1416 \\
\hline
\end{tabular}

Source: Authors' Construct

\section{Study Design and Sampling}

The study forms part of a larger research that assessed the effects of environmental sustainability practices on the growth of manufacturing companies in the Ashanti region of Ghana. The study adopted an organisation based survey design by which six manufacturing companies owing to their 'how' and to 'what' extent of sustainability practices were selected. Again, the study focused on contemporary issues such as green technologies and environmental sustainability practices of manufacturing companies hence, survey design was desirable (Creswell and Creswell, 2017). According to Nsowah-Nuamah (2005), surveys are the systematic means of obtaining standardised information about the behaviour, attitudes and any other characteristics of a population being studied. In order to obtain answers to the research questions raised and at the same time achieving the objectives of the study and drawing valid conclusions, the researchers took into account a sample that was representative. A representative sample according to Babbie (2005) is a sample that bears all the characteristics of the population it is representing.

According to Frey et al. (2000), survey designs make use of large populations which are reduced step by step to samples. Such steps involve the identification of unit of analysis, specification of target and study populations, sample size determination and sample selection. All these processes were embarked upon in order that sampling errors would be minimised. Nevertheless, determining a sample size that would be equally representative of the population was also difficult. As a result, factors such as the population homogeneity or otherwise, fraction of the population constituting the sample and lastly the desired precision (margin of error) were considered in the determination of the sample size. Giving these factors, the margin of error for the determination of the sample size was 0.02 and the proportion of the study population likely to agree with the statement that environmental sustainability is a priority in the organisation was assumed to be $60 \%(0.60)$. The figures were then substituted into Moser and Kalton's formula for determining sample size. The formula is given as:

$$
\mathrm{n}=\frac{\mathrm{P}^{1}\left(1-\mathrm{P}^{1}\right)}{\left[\mathrm{SE}_{\mathrm{p}}\right]^{2}}
$$


where $\mathrm{P}^{1}=$ estimate of proportion of the population with a particular characteristic.

$\mathrm{SEp}=$ acceptable margin of error $\mathrm{n}=$ sample

$\mathrm{n}=\frac{0.60(1-0.60)}{[0.02]^{2}}$. Therefore, the sample size for the study was 600 .

The fractional approach also suggests that any fraction of the population that is $10 \%$ or more is deemed large enough to be a representative sample, especially if the sample is scientifically selected (Monette, 2005 cited in Babbie, 2005). Furthermore, Bush and Burns (2000) concluded that a sample size of 5\% of a population of study is likely to achieve its purpose if it was scientifically chosen. The sample size of the study was about $42.4 \%$ of the total study population of 1,416. For this reason, the sample size of 600 respondents made up of the management, senior and junior staff of the selected organisations is considered adequate for the study. Vivian (2003), also supports this argument by stating that statisticians have found that 384 is a magic number for many surveys even if the population size is infinite because it is derived from a 5\% margin of error. This margin of error decreases as the sample size increases beyond 384. Therefore, this sample size is considered adequate to yield the expected result, more especially, where the sample was selected scientifically by means of stratified sampling technique.

\section{Sampling technique}

In the first stage, all the targeted MCs were grouped under the major manufacturing industries in the region that they belong to. They were companies engaging in wood processing, pharmaceutical, animal feeds processing, food and meat processing, drinks and beverages as well as oil processing. Cluster sampling was used to select the five manufacturing companies in the Ashanti region which were listed by the EPA as the worse performing organisations in environmental sustainability practices. The remaining organisation (Coca-Cola Bottling Co.) was purposively chosen because it was the only manufacturing company whose operations in the region were rated satisfactory. Therefore, its inclusion was meant to serve as a control group to the other five organisations. The MCs were thus selected based on the major manufacturing industries in the region that they belong to. As such each company selected represented a cluster of companies in the manufacturing sector with common environmental sustainability practices in accordance with the EPA specifications. Furthermore, the choice of different companies was based on the assertion that using exclusively, organisations which have implemented environmental sustainability practices would mean that the sample will not vary on sustainability practices (Christmann, 2000).

In the second stage of the sampling process, proportional stratified sampling (Proportionate sample allocation) technique was used after clustering the manufacturing companies into wood processing, pharmaceutical, animal feeds processing, food and meat processing, drinks and beverages as well as oil processing. Akuoko (2008) has stated that when the population consists of a number of subgroups (strata) that are heterogeneous in nature, it is often appropriate to use stratified sampling in order to cater for the variability in the population. It is a probability sampling design in which the population is first divided into homogenous strata and a sample is selected from each stratum. In stratified sampling researchers first divide the population into sub- groups and from each stratum they select a certain number of sample units to form the sample.

Bearing this in mind, a mathematical formula was applied in obtaining the proportion of each stratum (each company) of the study population to constitute the sample. The formula for determining the sample allocation for each stratum in the sample was given as:

$$
\begin{aligned}
& \mathrm{ni}=\frac{\mathrm{Ni} \cdot n}{\mathrm{~N}} \\
& \mathrm{i}=1,2 \ldots 6 \\
& \mathrm{n} 1=\frac{\mathrm{N} 1}{\mathrm{~N}} \cdot \mathrm{n} \\
& \mathrm{n} 2=\frac{\mathrm{N} 2}{\mathrm{~N}} \cdot \mathrm{n} \\
& \mathrm{n} 6=\frac{\mathrm{N} 6}{\mathrm{~N}} \cdot \mathrm{n}
\end{aligned}
$$

Where Ni is the total population of each company, $\mathrm{N}$ is the total population of the six (6) companies. 
$\mathrm{n}$ is the sample size.

$\mathrm{ni}$ is the sample allocation for each stratum (company)

Table 1: Sample size for each of the selected companies

\begin{tabular}{|l|l|l|l|}
\hline Organisation & $\mathrm{Ni}$ & $\mathrm{N} \mid \mathrm{n}$ & $\mathrm{ni}=\underline{\mathrm{Ni}} \cdot \mathrm{n}$ \\
\hline BLLC & 300 & $1416 \mid 600$ & 127 \\
\hline AC & 186 & $1416 \mid 600$ & 79 \\
\hline AEP & 224 & $1416 \mid 600$ & 95 \\
\hline KA & 159 & $1416 \mid 600$ & 67 \\
\hline CBC & 360 & $1416 \mid 600$ & 153 \\
\hline JOM & 187 & $1416 \mid 600$ & 79 \\
\hline
\end{tabular}

Source: Authors' Construct

\section{Data Collection}

Two instruments were used to capture information for analysis in the study. They were questionnaires and keyinformants' interviews. However, the main instrument used for the data collection was questionnaire. The questionnaire was the only quantitative data collection instrument used and was designed based on the objectives of the study. The questionnaire was made up of open and close-ended questions. The close-ended question allowed respondents to answer question by making a choice out of a list of options. The open-ended questions allows for flexibility in answering the question. It provides an opportunity for the respondents to provide their own responses to supplement the responses provided in the close-ended questions. Finally Likert scaled type of questions were also used in order to help measure variables at the interval level.

Semi-structured interview schedule or protocols were designed to elicit information from the key-informants to support the data from the questionnaire survey. Notwithstanding, these two major data collection methods, direct observation was resorted to in certain situations to collect data to confirm the data gathered from the administration of the questionnaires and the key-informants' interviews. This was in conformity to Bhattacherjee (2012 assertion that personal observation is important in social research.

\section{Data Collection and analysis}

It is noted that the king pin of any scientific research is the accuracy of the analysis of its data. Bush and Burns (2000) agreed the more when they said that it was the most important aspect of any research and ought to be done critically and technically. In this regard, the questionnaire and the interview protocol were scrutinized by the authors to make sure that they did not have errors to influence the validity of the results. Kothari (1994) indicated that editing of data involves critical examination of the raw data gathered from the field in order to identify errors and omissions and correct them to ensure that the data collected are accurate. Babbie (2005) believes that editing involves going through data in order to find out inconsistencies and errors. After editing the responses to the openended questions, they were then coded when agreement was reached just as the responses to the close-ended questions had been. The coding process involved categorising responses and assigning numbers to responses so that they could be put into one exclusive category. Coding was followed by the data cleaning. Cleaning data involved a critical search for coding errors identified as being impossible and improbable based on the way the variables were defined. Hereafter, a carefully scrutinised coding scheme was developed. The Statistical Package for Social Sciences (SPSS) software was used in processing quantitative data for analysis. As a result the variables and their coded attributes or values were keyed in the computer for SPSS software programme to process them for analysis. Both descriptive and inferential statistical components of SPSS were utilised. Through the descriptive statistics result were presented using tables and chi- square, Pearson $r$ as well as ANOVA were used to test for correlations and levels of significance.

\section{Results and Discussion}

One of the main objectives of the study was to find out effects of ESPs on socio-economic performance of MCs in Ashanti region. The inclusion of this objective was meant to clarify uncertainty as to the real effects of ESPs on the performance of MCs. The conviction of the authors of this study was that by ascertaining the real effects of ESPs would facilitate the conclusion as to why most of the MCs in Ashanti region failed to keep up with the environmental sustainability standards set out by EPA. Elite theory of public policy according to Wilson (2006) assumes that business leaders or corporate interest dominate policy processes. Therefore, if these corporate bodies are fully aware of the effects of ESPs on their business performance, they may or may not commit themselves to keeping best ESPs. They may employ all means to influence the direction of any policy that affects their interest. Some contemporary studies have concluded that ESPs have no effect on social and economic performance of organisations in general. Companies therefore, engage in ESPs as a matter of morality (Hibbert and Cunliffe, 2015). It is even believed that employees comply with ESPs for the sake of organisational citizenship. Others are also of 
the view that ESPs of companies enhance their public relations leading to reduction in the cost of production (Landrum and Edwards, 2009). Swarbrooke and Horner (2007) indicated that it creates competitive advantage for new market opportunities thereby enhancing the chance for good return on capital employed. Sheng (2018) on the other hand asserted that it leads to decrease in profit margin because of the cost involved.

This grey area needed a clarification in order to ascertain the real effects of ESPs on MCs in the Ashanti region to facilitate the conclusion as to why MCs are not committed to maintaining best ESPs. As result respondents were asked to indicate their level of agreement with some statements meant to test the effects of ESPs on the socio-economic performance of the MCs. The Likert scale type of questions was designed to enable the variable- effects of ESPs on the socio-economic performance of the MCs- to be measured at the interval level. The variable was measured at that level so that means and standard deviations could be used to analyse the data. It is observed therefore, from the Table 3 that ESPs have some effects on the socio-economic performance of the MCs in the Ashanti region. The grand mean (3.1830) was used at some point as the base mean with which the means of the various socio-economic performances were compared. By so doing, the magnitude of these performances was revealed.

\section{Economic Performance of the Manufacturing Companies}

The economic performance of the MCs was observed through the following indicators; increasing competitiveness leading to a good return on capital employed, decreasing cost of production in the short run and increased profit margin of the MC. These indicators were linked to the ESPs.

The economic performance in areas of cost reduction in the short run and enhanced competitiveness of the MC leading to a good return on capital employed were found to be somewhat the same in the selected companies. It was worse in the rise in profit margin. There was not enough evidence from the Table to support the claim that at least the MCs were able to maintain their competitiveness and good return on the capital employed. The Table showed that maintaining best ESPs reduced the profit margin of the MCs $(M=1.1930 ; \mathrm{S}=.4933)$. In other words MCs' performance in terms of increasing profit margin as a result of ESPs was not encouraging. In that regard, the companies performed unsatisfactorily in the period under consideration. This implies that the MCs could not use ESPs to increase their profit margin rather their profit margins decreased. Similarly, as observed from the Table, having best ESPs is more likely to maintain cost of production in the short run $(\mathrm{M}=3.3758 ; \mathrm{S}=.78410)$. Table 3. Item Statistics on ESPs and socio-economic performance of MCs

\begin{tabular}{|c|c|c|c|}
\hline & Mean & Std. Deviation & $\mathrm{N}$ \\
\hline \multicolumn{4}{|l|}{ Economic performance } \\
\hline ESPs enhanced MCs competitiveness and a good return on capital employed & 2.8322 & 1.01520 & 596 \\
\hline ESPs decreased cost of production in the short run & 3.3758 & .78410 & 596 \\
\hline ESPs increased the profit margin of the MC. & 1.1930 & .49333 & 596 \\
\hline \multicolumn{4}{|l|}{ Social performance } \\
\hline ESPs lead to positive public relations & 3.2450 & .49575 & 596 \\
\hline Good ESPs improve corporate image with stakeholders and the local community & $\begin{array}{l}3.6292 \\
3.2836 \\
\end{array}$ & $\begin{array}{l}1.14279 \\
1.13986 \\
\end{array}$ & \\
\hline \multicolumn{4}{|l|}{ ESPs and conflict reduction between the MC and the community } \\
\hline ESPs and the reputation people attach to & 2.8221 & 1.20583 & \\
\hline
\end{tabular}

Source: Author's Construct

As a result, maintaining best ESPs has great magnitude of effects on the socio-economic performance of the MCs. This implies that MCs that endeavour to keep best ESPs risk a decline in profit margin at least in the short run. This situation was confirmed by the Northern sector Manager of Coca Cola Ghana Limited in an interview when He said, "having best environmental sustainability practices is expensive".

\section{Social performance}

In the area of social performance which was measured in terms of positive public relations $(\mathrm{M}=3.2450)$, improved corporate image with stakeholders and the local community $(\mathrm{M}=3.6292)$, conflict reduction between the MCs and the community $(\mathrm{M}=3.2836)$ and reputation people attach to the $\mathrm{MC}$ were found to be the same. Respondents indicated that there had not been any significant variation in social performance of the MCs compared to the years preceding the last four as depicted in Table 3. With regard to the reputation people attach to the company, Table 3 depicts that the MCs have not been able to use the ESPs to gain or improve upon the reputation people attach to the company $(\mathrm{M}=2.8221 ; \mathrm{S}=1.20583)$. 
ESPs and Socio- economic performance of the MC

Inferential statistics was employed to examine the effects of the various ESPs on the economic performance of manufacturing companies. Economic performance in this context was measured in terms of the profit margin (the percentage of revenue remaining after all the expenses have been deducted) of the MCs. Profit margin was used to determine the effects of ESPs on economic performance of the MCs because the survival of a company largely depends on its profit margin. Linear regression was used to predict the relationship between the ESPs and the company's profit margin. The dependent variable- profit margin of the company was measured in percentages given by the respondents which were later on converted mechanically into log for the purpose of linearisation. The independent variable (ESPs) on the other hand was measured by ranking them on a scale of 1 to 5 because that variable had five attributes or indicators. The set of ESPs with the highest toll on profit margin according to the respondents was given a score of 5 whereas the least scored 1. It should be noted that the authors were mindful of the likelihood of respondents guessing the effect of the ESPs on the profit of the company, so they were asked to indicate the source of their information. To further validate the information, the finance officers of the six MCs were called upon to authenticate the responses and where necessary some adjustments were made. The result of the regression analysis is summarised in Tables 4 and 5.

Table 4: Model Summary of the Effects of ESPs on the economic performance of MCs

\begin{tabular}{|l|l|l|l|}
\hline $\mathrm{R}$ & R Square & Adjusted R Square & Std error of the estimate \\
\hline 0.902 & 0.813 & 0.657 & 0.371 \\
\hline
\end{tabular}

Source: Author's construct.

The information in Table 4 presents a summary of the regression model employed in the analysis of the relationship between profit margin of the company and the utilisation of the various ESPs. The R square of 0.813 means that the model explains about $81.3 \%$ of the variations in the dependent variable. In other words, about $81.3 \%$ of the dependent variable (profit margin) is due to the independent variable (ESPs). Even where adjustments were made for errors, about $65.7 \%$ of the variations in the dependent variable is accounted for by the independent variable. Furthermore, one could observe relationships as depicted in the Table 5 in respect of the regression coefficients of the predictor variables.

Table 5: Regression Coefficients of the Predictor Variable.

\begin{tabular}{|l|l|l|l|}
\hline Predictor Variable & B & $\begin{array}{l}\text { Std. } \\
\text { Error }\end{array}$ & $\begin{array}{l}\text { P- } \\
\text { value }\end{array}$ \\
\hline Constant & 0.592 & 0.238 & 0.010 \\
\hline Traditional practices such as using chimneys, rubbish bin and clean-ups & $0.041^{* *}$ & 0.390 & 0.352 \\
\hline $\begin{array}{l}\text { Installation of state of the art facilities to reduce pollution such as bio-digesters } \\
\text { for treating of liquid waste, kilns for drying wood etc }\end{array}$ & - & 0.020 & 0.003 \\
\hline $\begin{array}{l}\text { The use of fume-free machinery such as LPG powered and energy } \\
\text { conservation machines. }\end{array}$ & $-0.103^{* *}$ & 0.021 & 0.012 \\
\hline Environmental and waste management policy (reuse, recycling etc) & $0.021^{* *}$ & 0.003 & 0.000 \\
\hline $\begin{array}{l}\text { Environmental socialisation (workshops, seminars, conferences etc) and Eco- } \\
\text { awards. }\end{array}$ & $-0.063^{* *}$ & 0.025 & 0.021 \\
\hline
\end{tabular}

Dependent variable: Log of profit margin (\%), statistical significance : $<0.01(* * *)$ and $<0.05(* *)$

It is important to note that the negative coefficient implies that a $100 \%$ increase in the use of that particular practice will reduce the profit margin of the company by a percentage point equivalent to the coefficient multiplied by 100 . The positive coefficient means that $100 \%$ increase in the use of that particular practice will increase their profit margin by a percentage point equivalent to the coefficient multiplied by 100 .

It is seen in the Table 5 that the companies, which engage in traditional ESPs such as using chimneys, rubbish bins and clean-ups are likely to increase their profit margin by $4.1 \%$. However, the coefficient of 0.041 is not significant at 0.05 because the p-value was 0.352 which is greater than 0.05 . This means that variability among scores is wide and the result may not be valid and reliable. It gives an indication that there are other significant variables or factors that influence the equation or the situation and that the means that were used in determining the line of best fit were wide apart from the scores that produce them. The other explanation to this situation is that the practice itself may not contribute to the company's profit but the fact that these traditional practices involve the use of less costly materials and so a slight increase in output is likely to increase profit. Therefore, without a critical analysis such increase in profit could be attributed to the ESPs. Nevertheless, the practice has the tendency to increase the firm's profit margin perhaps due to low cost of engaging in such traditional practices and the public relations aspects of it. The observation confirms an earlier finding by Christmann (2000), Jasch, and Savage (2005) that environment- related cost is high and for that matter, companies engage in ESPs that are likely to increase or maintain their profit.

Again, Table 5 also presented a regression analysis on installation of state of the art facilities to reduce pollution (such as bio-digesters for treating of liquid waste, kilns for drying wood etc) and profit margin of the 
company. The result shows that companies, which install state of the art facilities to reduce pollution, are likely to decrease their profit margin by $6 \%$. This relationship was inferred from the regression coefficient of -0.060 , which was significant at 0.01 with a p-value of 0.003 . Similarly, the Hannover Chamber of Commerce found that materials including environmental sustainability practices currently accounted for $40 \%$ of the costs in manufacturing industries as compared to labour, which accounts for $23 \%$ of the total cost (Jasch and Savage, 2005). Therefore, the prediction is more likely to be accurate. This evidence proves that the probability of losing $6 \%$ of the profit of the company to environmental sustainability is high and therefore, management is more likely to cut corners to avoid that cost. This could account for why MCs fail to meet EPA environmental sustainability standards because they could not risk losing about $6 \%$ of their profit.

In the case of the use of fume free machinery such as LPG powered and energy conservation machines, the result from the regression analysis indicates that such a practice significantly reduces profit margin of companies. Statistically, the analysis reveals that $100 \%$ increase in the use of this practice reduces the profit margin of the companies by $10.3 \%$ and this was significant at 0.05 . The reason for this state of affairs according to Wonglimpiyarat, (2016) is the high cost of these machines, which eventually increases total cost of production.

The analysis also revealed that having environmental and waste management policy including reuse and recycling is likely to increase profit margin by $2.1 \%$, which was significant at 0.05 with p-value of 0.000 . Earlier study by Wonglimpiyarat, (2016) has established that having environmental policy in a company would keep employees informed about their environmental roles and responsibilities. It also improves cost control, reduces incidents that result in liability, conserves raw materials and energy, improves monitoring of environmental impacts and lastly improves the efficiency of processes (EnvironmentalManagementSystem.com.au 2010-15, retrieved on $12|12| 2017)$.

In view of the aforementioned benefits of having environmental policy, it is therefore, not out of place that this study discovered that having environmental and waste management policy increases profit by $2.1 \%$. Furthermore, it is explained that environmental policies could stimulate innovation and investment in innovation by internalising the external costs of pollution and natural resource use. Policies could change relative prices and stimulate research and development as well as the uptake of alternative inputs, production methods and products.

In the same way, environmental policies lead to innovations in conservation of resources and energy; pollution prevention and environmental clean-up. These innovations were found to have the potential to reduce cost and reinforce the competitiveness of EU industries, because 'clean' technologies developed in Europe have become successful export products in the world. It has been established that policies induced by environmental innovations have directly and indirectly engendered, competitiveness, growth and job creation in the companies (Wonglimpiyarat, 2016). These writers have also observed that European Commission had estimated that the total commercial value of eco-innovative products and technologies in sustainable construction, renewable energy, biobased products and recycling in the EU could grow from $€ 92$ billion in 2006 to $€ 259$ billion in 2020, thereby creating more than 2.4 million new jobs.

Finally yet importantly is the use of environmental socialisation (workshops, seminars, conferences etc) and eco-awards strategies to achieve environmental sustainability. It also revealed that such practices are likely to decrease the profit of the company by $6.3 \%$, significant at 0.05 . This could be explained in terms of the cost involved in organising such events. The analysis has so far established that some ESPs such as environmental and waste management policy on reuse, recycling etc and engaging in traditional ESPs such as using chimneys, rubbish bins and clean-ups are likely to increase profit margins. Environmental socialisation (workshops, seminars, conferences etc) and Eco-awards strategies to achieve environmental sustainability, installation of state of the art facilities to reduce pollution and the use of fume-free machinery such as LPG powered and energy conservation machines on the other hand decrease profit margin of MCs. This observation therefore corroborates the previous findings by some environmental researchers that ESPs have both positive and negative effect on the finances of companies and therefore, the socio-economic performance of such companies. Landrum and Edwards, (2009); Hitchcock and Willard (2009) are even of the view that positive implications ESPs have on the performance of companies are both short term and long term.

The next in magnitude in terms of the effects of the ESPs on the socio-economic performance of MCs is whether or not ESPs improve corporate image with stakeholders and local community $(\mathrm{M}=3.6292 ; \mathrm{S}=1.1428)$. This advantage has always been the reason behind Che's (2011) call on firms to embark on best ESPs. As to whether this advantage comes with financial realities is another matter as alluded to by the environmental officer at BLLC, Kumasi. There were other effects which were considered minor because their means were below the grand mean. The minor effects included poor ESPs resulting in conflict between the organisations and their communities $(\mathrm{M}=3.2836 ; \mathrm{S}=1.1399)$. An interview with one of the assembly members in Juabeng provided an evidence of why poor ESPs of the MCs have not been met with stronger opposition from the communities. He said that those MCs had stronger link with political leaders and the police high commands who were ready to defend and protect them at all times. Other minor effects were that ESPs reduce cost in the long run but increases cost in the short run $(\mathrm{M}=3.3758, \mathrm{~S}=.7841)$ and best ESPs may lead to positive public relations. It is also observed from 
Table 3 that the effect of ESPs on the reputation people have for the company $(\mathrm{M}=2.8221 ; \mathrm{S}=1.2058)$ is insignificant because it is far below the grand mean of 3.4830. This implies that whether or not these MCs develop and keep best ESPs, their reputation is not at risk.

Further examination and analysis of the data confirmed the $\mathrm{H}_{2}$ : There is a significant negative relationship between environmental sustainability practices and economic performance of the MCs. There was a strong negative correlation of -0.6 between the ESPs and the company's socio-economic performance. The correlation coefficient was significant at 0.01 level. The negative correlation implies that as the cost of maintaining ESPs increases the MCs plans to improve their socio-economic performance decline. This relationship is observed in the Table 6 below. This evidence thus corroborates the earlier findings by Che (2011) that environmental sustainability issues decrease corporate's profit margins and the company's performance. As a result of this correlation there is a high probability of saying that companies are more likely to pay less attention to best ESPs since their improvement may have a negative effect on their financial base. This finding among others may explain why many of MCs have successively failed environmental sustainability tests.

Table 6: The correlation between ESPs and economic performance of MCs

\begin{tabular}{|c|c|c|}
\hline & $\begin{array}{lr}\text { Cost } & \text { of } \\
\text { maintaining } & \text { ESPs } \\
\text { in the } \mathrm{MC} & \\
\end{array}$ & $\begin{array}{l}\text { Improving economic performance } \\
\text { of } \mathrm{MC}\end{array}$ \\
\hline 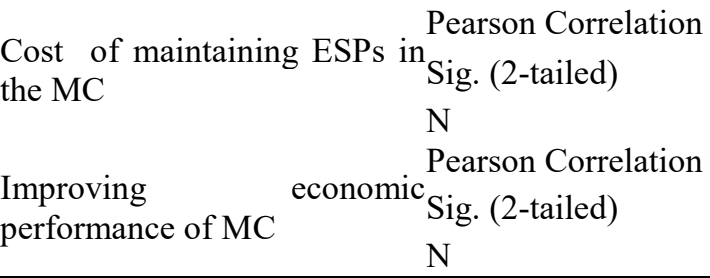 & $\begin{array}{l}1 \\
596 \\
-0.550^{* *} \\
.000 \\
596\end{array}$ & $\begin{array}{l}-0.550^{* *} \\
.000 \\
596 \\
1 \\
596\end{array}$ \\
\hline
\end{tabular}

**. Correlation is significant at the 0.01 level (2-tailed).

Source: Author's construct

Furthermore, a non-parametric statistical test was run to test the $\mathrm{H}_{1}$ : Environmental sustainability practices significantly enhance socio-economic performance of the MCs. Non parametric test was considered appropriate because the test did not make any assumption about the shape of the distribution of scores in the population. The result of this test is shown in the Table 7 below.

Table 7: Non Parametric Test Summary of ESPs Enhancing Socio-economic performance of MCs.

\begin{tabular}{|l|l|l|l|}
\hline $\mathrm{H}^{\circ}$ & Test & Sig & Decision \\
\hline $\begin{array}{l}\text { ESPs enhance socio-economic performance of MCs. } \\
\text { Distribution is normal with } \mathrm{M}=3.832 \text { and } \mathrm{S}=1.02 .\end{array}$ & $\begin{array}{l}\text { One-sample Kolmogorov- } \\
\text { smimov test }\end{array}$ & .000 & $\begin{array}{l}\text { Reject the } \\
\mathrm{H}^{\circ}\end{array}$ \\
\hline
\end{tabular}

Source: Author's construct.

Kolmogorov-Smimov test assumes a normal distribution of the sample scores. The test result shows that the distribution of ESPs as a means of enhancing socio-economic performance is normal with $\mathrm{M}=3.83$ and $\mathrm{S}=1.02$. Since the distribution is normal, the $\mathrm{HO}$ is rejected and concluded that ESPs do not enhance socio-economic performance of the selected MCs in the Ashanti region. This probably accounted for why many of the MCs failed to meet EPA standards in 2009 and failed the criteria in 2012. Even though the data have shown that, some ESPs have positive effect on the socio-economic performance of the MCs. Overall, such individual effects are not significant enough to offset the negative aggregate effects of the ESPs on the performance of the MCs. This observation is in agreement with the research of Aldakhil et al., (2018) where the null hypothesis of no causality was rejected based on significant probability.

\section{CONCLUSIONS}

The current study provides an insight into the nature of socio-economic performance of manufacturing companies in the Ashanti region of Ghana. The study used data from a sample of 600 respondents from 6 companies which were listed by the EPA of Ghana for environmental sustainability assessment. The research intended to ascertain the nature, challenges, effects and the socio-economic performance of manufacturing companies. The motivation for this study stemmed from the non-compliance with EPA's environmental sustainability standards by manufacturing companies in the Ashanti region in 2009 and 2012. The study sought to find out why almost all the manufacturing companies in the region performed badly in the assessment by EPA. Among other outcomes, the study therefore, found that manufacturing companies for the purposes of incorporation and renewal of incorporation, develop environmental sustainability practices, EPA inspections were considered as mere formality, and most of the MCs do not have environmental protection departments let alone having sustainability officers to manage them. The study concluded that there is a general negative correlation between socio-economic 
performance and ESPs of MCs. Hence, MCs that strictly comply with the EPA'S environmental sustainability package are likely to have negative consequences on their socio-economic performance. The study, therefore, recommends that the EPA as an institution of state should adopt homegrown measures that are environmentally friendly in the environmental sustainability packages under their control. Again, the Ministry of Environment, Science, Technology and Innovation together with the EPA should conduct routine inspections on the compliance with the environmental sustainability standards by manufacturing companies. There should also be tax exemptions for companies which perform satisfactorily on the environmental sustainability test.

Ethics approval and consent to participate

All participants were above 16 years and formal written informed consent was obtained from each before their participation.

\section{Consent for Publication}

Not applicable

\section{Availability of data and material \\ Not applicable}

\section{Competing interests}

The authors declare that there is no conflict of interests regarding the publication of this paper.

\section{Funding}

The authors received no funding for this research paper.

\section{Author's contribution}

$\mathrm{KBB}$ is the Principal Investigator of the study and participated in its conception and design. HKM and KBB carried out the literature review and drafted the entire manuscript. JAA contributed in the conception and design of the study and closely reviewed the analysis and manuscript. Both KBB and JAA participated in revising and finalising the manuscript. All authors read and approved the final manuscript especially in the coding stage.

\section{Acknowledgements}

The authors wholeheartedly thank all staff of manufacturing companies who sincerely helped to collect data for analysis. The authors are also grateful to Managing Directors of the selected companies for their support.

\section{References}

1, Aldakhil, A. M., Nassani, A. A., Awan, U., Abro, M. M. Q., \& Zaman, K. (2018). Determinants of green logistics in BRICS countries: An integrated supply chain model for green business. Journal of Cleaner Production, 195, 861-868.

2. Akuoko, K. O. Bour, K. B. (2013). Effects of mining pollution on the people of Wassa West District of Ghana. ZENITH International Journal of Multidisciplinary Research, 3(2), 330-344.

3. Amanor, K., Brown, D. (2003). Marking environmental management more responsive to local needs: Decentralisation and evidence-based policies in Ghana. London, overseas development institute.

4. Andrew Thomas, Paul Byard, Mark Francis, Ron Fisher, Gareth R.T. White. (2016). Profiling the resiliency and sustainability of UK manufacturing companies, Journal of Manufacturing Technology Management, Vol. 27 Iss 1 pp. $82-99$

5. Babbie, E. (2005). The Basics of Research. Belmont, Thomson Wadsworth.

6. Barr, S. (2016). Environment and society: Sustainability, policy and the citizen. Routledge.

7. Beinart, W. (2000). African history and environmental history. Oxford, Oxford University press.

8. Bhattacherjee, A. (2012). Social science research: Principles, methods, and practices. Cambridge, University Press.

9. Boons, F., Montalvo, C., Quist, J., Wagner, M. (2013). Sustainable innovation, business models and economic performance: an overview. Journal of Cleaner Production, 45, 1-8.

10. Che, A. M. (2011). Ensuring environmental sustainability in the printing industry. Uppsala, SLU.

11. Christmann, P. (2000). Effects of "best practices" of environmental management on cost advantage: The role of complementary assets. Academy of Management journal, 43(4).

12. Creswell, J. W., Creswell, J. D. (2017). Research design: Qualitative, quantitative, and mixed methods approaches. Sage publications.

13. EPA- Akoben (2012). Report Rating on Environmental Sustainability Practices of Manufacturing organisations in Ghana. 
14. Ghana Statistical Service (2012). 2010 population and housing census summary report of results.

15. Hibbert, P., Cunliffe, A. (2015). Responsible management: Engaging moral reflexive practice through threshold concepts. Journal of business ethics, 127(1), 177-188.

16. Hörisch, J., Freeman, R. E., Schaltegger, S. (2014). Applying stakeholder theory in sustainability management: Links, similarities, dissimilarities, and a conceptual framework. Organisation \& Environment, 27(4), 328-346.

17. Karcagi-Kovats, A. (2012). Performance indicators in CSR and sustainability reports in Hungary. Applied Studies in Agribusiness and Commerce, 6, 3-4.

18. Kothari, C. R. (2004). Research methodology: Methods and techniques. New Age International.

19. Kouakou, B. (2013). Cocoa crops are destroying the forest reserves of the classified forest of

HautSassandra (Ivory Coast) Global Ecology and Conservation, vol. 8.

20. Kpelle, M., Alhassan, F. Sakara, A. (2014). The Effects of Manufacturing Industry on the Environment: case of Atonsu-Kaase-Ahinsan in the Ashanti Region of Ghana. ADRRI Journal of Physical and Natural Sciences, Ghana: Vol. 1, No. 1(1).

21. Kpelle, M., Alhassan, F. Sakara, A. (2014). The Effects of Manufacturing Industry on the Environment: case of Atonsu-Kaase-Ahinsan in the Ashanti Region of Ghana. ADRRI Journal of Physical and Natural Sciences, Ghana: Vol. 1, No. 1(1).

22. Marfo, K. Anchirinah, V. (2004). Protecting the people or the forest? Environmental policies and livelihoods in the forest margins of southern Ghana. London, Overseas Development Institute.

23. Mayamurugan, R. (2016). ISO 14001: Environmental Management System. In Integrated Waste Management in India (pp. 117-121). Springer, Cham.

24. Mayamurugan, R. (2016). ISO 14001: Environmental Management System. In Integrated Waste Management in India (pp. 117-121). Springer, Cham.

25. Montalvo, C., Tang, P., Mollas-Gallart, J., Vivarelli, M., Marsilli, O., Hoogendorn, J., Butter, M., Jansen, G., Braun, A. (Eds.), (2006). Driving Factors and Challenges for EU Industry and the Role of R\&D and Innovation. European Techno-Economic Policy Support Network, Brussels (ETEPS AISBL Report to the European Commission Directorate General Joint Research Centre e IPTS, Seville.

26. Nsowah-Nuamah, N. N. N. (2005). Basic statistics: A handbook of descriptive statistics for social and biological sciences.

27. Paiva, E.L., Gutierrez, E.R. Roth, A.V. (2012). Manufacturing strategy process and organisational knowledge: a cross-country analysis, Journal of Knowledge Management,

28. Vol. 16 No. 2, pp. 302-328.

29. Rao, P., Holt, D. (2005). Do green supply chains lead to competitiveness and economic performance? International journal of operations \& production management, 25(9), 898-916.

30. Sheng, S. (2018, October). Comparative Analysis on the Profitability of Listed Companies-A Case Study of Vanke Group. In 2018 3rd International Conference on Politics, Economics and Law (ICPEL 2018). Atlantis Press.

31. Songsore, J. (2004). Urbanisation and health in Africa: Exploring interconnections between poverty, inequality and the burden of disease. Accra, Ghana Universities press.

32. Swarbrooke, J., Horner, S. (2007). Consumer behaviour in tourism. Routledge.UNEP (2013). Green Economy coping study: Ghana.

33. Wilson, C. A. (2006). Public policy: continuity and change. New York, McGraw-Hill.

34. Wonglimpiyarat, J. (2016). Government policies towards Israel's high-tech powerhouse. Technovation, 52, 18-27. 